\title{
Neurohormones: oxytocin, vasopressin and related peptides - structure, genes, receptors, and evolution
}

\author{
K. Kochman \\ The Kielanowski Institute of Animal Physiology and Nutrition, Polish Academy of Sciences \\ 05-110 Jabłonna, Poland \\ Considered biologically as well as philosophically, man is \\ a most singular product of the evolutionary process. \\ He receives and transmits not one but two heredities, \\ the biological and the cultural. Man's biological heredity is very \\ much like that of any other organism; it is transmitted solely \\ from parents to their children, and to other direct descendants. \\ Cultural heredity, or simply culture, is transmitted by \\ teaching, imitation, learning, in large part by means of language. \\ Theodosius Dobzhansky, 'Heredity and the Nature of Man'
}

François Jacobs, 'Evolution is molecular tinkering'

KEY WORDS: neuropeptides, oxytocin, vasopressin, neural-lobe of pituitary, receptors, evolution

Received: 6 May 2013

Revised: 5 October 2013

Accepted: 11 November 2013
ABSTRACT. Oxytocin (OT) and vasopressin (VP), and all related hormones, consist of nine amino acids with cysteine residues in positions 1 and 6 that form a six-amino acid cyclic part, and of a C-terminal glycine in a-amidated form. These neuropeptides are classified into oxytocin and vasopressin families based on the amino acid residue at position 8. OT-like and VP-like peptides are present in every vertebrate species. These peptides are a very ancient family of hormones having representatives in diverse species of invertebrates. Invertebrates have either a vasopressin-family peptide or an oxytocin-family peptide, whereas bony fishes, the ancestors of land vertebrates, have both isotocin and vasotocin. Presently, two evolutionary structural lineages have been proposed: an isotocin-mesotocin-OT line, associated with reproductive functions, and a vasotocin-VP line participating in water homeostasis. The ancestral gene encoding the precursor protein has been present in the animal genome for a period exceeding 500 million years of evolution. The exceptionally high stability of this structure of nine-amino acid peptides during the entire process of evolution suggests very powerful selective pressure, possibly by evolution together with respective receptors and specific processing enzymes. A novel gene with a distinct function and expression appeared during evolution through duplication of an ancestral gene. The synteny and order of genes in the neurohypophysial hormone gene locus are conserved in the lamprey, elephant shark, coelacanth, and tetrapods, but disrupted in teleost fishes presumably due to the rearrangements facilitated by a whole-genome duplication event in the teleost fish ancestor. 


\section{Introduction}

Vasopressin (VP) and oxytocin (OT), very important neuropeptides of the hypothalamus and neural lobe of the pituitary (NL), are synthesized in particular groups of neurons (nuclei) of the hypothalamus, which play a role in the maintenance and regulation of physiological systems and, in turn, are under specific regulatory mechanisms. They are synthesized as prepropeptide precursors in the cell bodies of hypothalamic neurons. After translocation into the endoplasmic reticulum (ER), the prepropeptide is sorted (de Bree et al., 2000) and packaged into dense core granules of the regulated secretory pathway in the trans-Golgi network (TGN). Subsequent processing events occur as the granules are transported down axons from the cell body to nerve terminals (Brownstein et al., 1980). The peptides are stored there until mobilized for secretion by physiological signals (Murphy and Wells, 2003).

The principal source of circulating vasopressin and oxytocin is the hypothalamo-neurohypopysial system (HNS), which consists of large magnocellular neurons (MCNs) of the supraoptic (SON) and paraventricular (PVN) hypothalamic nuclei that have axons terminating on the blood capillaries of the posterior pituitary (Bargman, 1966). Fully active oxytocin and vasopressin molecules are stored in neurosecretory vesicles before being released from the nerve terminals into the circulating blood according to physiological demand and signal.

The identification of specific mRNAs for oxytocin and vasopressin in the neural lobe (NL) of the rat pituitary gland (Murphy et al., 1989) stimulated much interest, research, and opinions concerning both their origin, regulation, and expected physiological role (Levy et al., 1990; Mohr et al., 1991; Murphy et al., 1993; Trembleau et al., 1994, 1996; Murphy and Wells, 2003). The mRNA for VP was also found in the neural lobe of mice (Murphy et al., 1989) and in the bovine neurointermediate lobe of the pituitary (Chaturvedi et al., 1996). The metabolism of VP mRNA and relations with the hypothalamic mRNA were studied. The poly(A) tail length of mRNA from the pituitary is shorter in comparison with the hypothalamic mRNA (Murphy et al., 1989). The concentration of this mRNA in the NL increases very significantly after osmotic stimulus and exceeds that in the hypothalamus; the poly(A) tail length of these transcripts in this situation was the same (Murphy et al., 1989). The cellular origin of these mRNAs is still unsolved and two possibilities are considered explaining their presence in the NL tissue (Murphy and Wells, 2003).
The first of these possibilities is axonal transport from the hypothalamus and localization in NL neural elements. The demonstration of vasopressin in a subset of axonal swellings in the median eminence and NL (Trembeau et al., 1994, 1996) supports the hypothesis that the VP mRNAs are transcribed in the neuronal cell bodies of the hypothalamus then transported down axons to the NL. Such a possible mechanism requires that hypothalamic VP mRNAs undergo poly(A) tail shortening during translocation, or that transport is limited to the VP mRNAs having short tails. The possible mechanism of such translocation is not known. The function of similar processes is also not understood, but two possible explanations have been proposed.

Gainer and Wray (1994) suggest that axonal transport of specific mRNAs may act as a 'molecular garbage shoot', rapidly carrying older (deadenylated) messages away from the neural perikaryons, but leaving newly synthesized mRNAs, which possess long poly (A) tails. Old, translationally effete $\mathrm{mR}$ NAs would, therefore, be efficiently replaced at the rough endoplasmic reticulum (RER) by molecules more efficient in the transcription process.

Bloom and co-workers suggested that the VP mRNA may serve as a possible signalling molecule, carrying necessary information encoded in the message up and down axons and, possibly, even postsynaptically (Murphy et al., 1992; MaciejewskiLenoir et al., 1993).

The second suggested possibility is that local synthesis takes place in pituitary cells, vascular or connective tissue, with expression velocity governed by neuroendocrine factors of hypothalamic origin (Levy et al., 1990).

Vasopressin mRNAs were identified in a subset of pituitary cells (Murphy et al., 1993), which is in concordance with the presence of their translation proteins in these cells (Boersma et al., 1993; Pu et al., 1995; Murphy and Wells, 2003).

Vasopressin plays a very important role in osmoregulation (Reeves and Andreoli 1992; Bourque et al., 1994). As a consequence of dehydration (complete fluid deprivation for up to 3 days) or salt loading (replacement of the normal drink in the diet with $2 \%(\mathrm{w} / \mathrm{v}) \mathrm{NaCl}$ for up to 12 days), rats responded to plasma hyperosmolality by reducing the renal excretion of water. Tubular reabsorption of water is controlled by circulating levels of vasopressin. The rise in plasma osmolality is detected by largely undefined osmoreceptor mechanisms in the circumventricular organs. In response to the excitation of hypothalamic neurons, vasopressin is released from stores in the axon terminals of the 
posterior pituitary. Vasopressin travels through the blood stream to its targets that exhibit specific receptors. In particular, through an interaction with V2-type receptors located in the kidney, vasopressin increases the permeability of the collecting ducts to water, promoting water conservation by decreasing the amount of water lost in urine. Perturbations in water balance also engender a functional demand for increased biosynthesis in order to replenish depleted stores of hormone in the posterior pituitary, transcription of the vasopressin gene increases (Arima et al., 1990; Murphy and Carter, 1990; Herman et al., 1991), and there is a concomitant two-fold increase in vasopressin mRNA content (Davies et al., 2003). In addition to its well-known roles in lactation (Van Tol et al., 1988) and, perhaps, parturition (Russell and Leng, 1998), oxytocin is involved in the control of salt excretion from the kidney (Verbalis et al., 1991; Huang et al., 1996).

While the SON contains only magnocellular neurons, the PVN is divided into a lateral magnocellular subdivision and a more medial parvocellular subdivision. Vasopressin, but not oxytocin, is synthesized in small cell bodies of neurons in the parvocellular division of the PVN that project to the external zone of the median eminence (Vandesande et al., 1977). Release of vasopressin into the hypophysial portal circulation results in the potentiation of corticotropin-releasing factor-induced adrenocorticotropin secretion from the anterior pituitary, which in turn regulates corticosterone secretion by the adrenal gland (Gillies et al., 1982). Vasopressin, but not oxytocin, is also found in the dorsomedial region of the suprachiasmatic nucleus (SCN), the circadian generator of the mammalian brain (Moore, 1983), where it is involved in the transmission of clock signals to the rest of the brain (Burbach et al., 1984; Zingg et al., 1986; Davies et al., 2003).

It is worth mentioning that copeptin (a fragment of the C- terminal of arginine-vasopressin (AVP) prohormone was found recently in human blood, especially in foetuses, and that its concentration may serve as a stable and sensitive indicator of AVP release. This peptide is additionally a good marker in the situation of pulmonary system infection, heart disease, and stroke (Burkhardt et al., 2012). Its concentration in foetal blood was 4-fold higher in the case of intrauterine growth restriction (IUGR) than in healthy subjects. A positive correlation of increased blood copeptin concentrations is found with stress after insufficient blood supply (Burkhardt et al., 2012).

Copeptin is co-synthesized with vasopressin and is present in plasma in similar levels as vaso- pressin. This peptide has been used as a diagnostic and prognostic marker in infections or other diseases. In patients with destabilized heart failure, copeptin was an accurate prognostic marker for mortality (Małyszko et al., 2010).

Studies on the physiological regulation of VP and OT gene expression in the hypothalamus have been facilitated by the well-established paradigms for the modulation of activity of these neurons. The experiments localized vasopressin and oxytocin gene expression in MCNs and showed it to increase in response to the functional demands of the organism. During pregnancy and lactation, when pituitary stores of oxytocin are often depleted, the abundance of oxytocin mRNA in the hypothalamus increases (Van Tol et al., 1988). Despite expression in distinct magnocellular neurons, the VP mRNA content also increases during pregnancy and lactation (Van Tol et al., 1988). Similarly, osmotic signals, such as salt-loading, resulting in functional demand for vasopressin, increase vasopressin gene transcription (Murphy and Carter, 1990; Herman et al., 1991) and mRNA abundance (Burbach et al., 1984; Zingg et al., 1986), and also result in stimulatory changes in oxytocin expression gene expression (Murphy and Carter, 1990). In the parvocellular PVN, vasopressin gene expression is suppressed by adrenal glucocorticoids as part of a negative-feedback loop, and is upregulated by stress (Ma et al., 1997), while diurnal cues modulate vasopressin gene expression in the suprachiasmatic nucleus (SCN) (Carter and Murphy, 1991; Murphy and Wells, 2003). Abundant and detailed information on the subject can be found in important and prestigious publications (Gainer and Wray, 1994; Acher, 1996; Hoyle, 1999; Gimpl and Fahreholtz, 2001; Gwee et al., 2009).

\section{Structure of vasopressin and oxytocin genes}

The genes for oxytocin and vasopressin are localized on the same chromosome, but are transcribed in opposite directions. The genes are linked loosely, tail-to-tail; these two genes are separated only by a short nucleotide region (IGR) of $11 \mathrm{kbp}$ in the rat (Schmitz et al., 1991), $3 \mathrm{kbp}$ in the mouse (Ratty et al., 1996) and $10 \mathrm{kbp}$ in humans (Gainer et al., 2001). Although the polymerase chain reaction shows VP and OT synthesis together in the same cells (Glasgow et al., 1999; Xi et al., 1999), the expression levels of individual neuropeptide mRNAs differ by orders of magnitude (Davies et al., 2003). This type of genomic arrangement is the result of the duplication of a common ancestral gene, which was followed by inversion of one of the genes. The human gene for OT-neurophysin I encoding the 


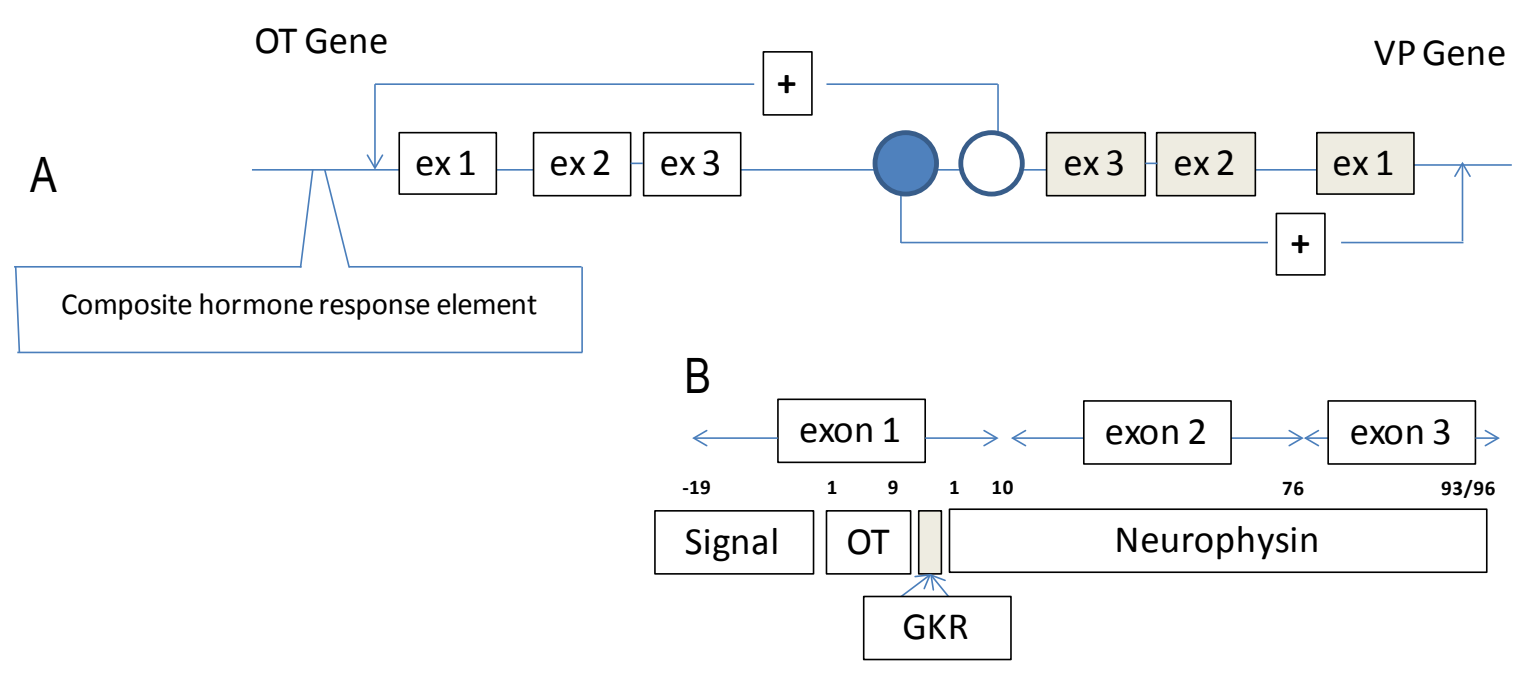

Figure 1. Organization of the oxytocin (OT) and vasopressin (VP) gene structure (Ivell et al., 1993; Gainer, 1998; Gimpl and Fahrenholtz, 2001; modified)

OT prepropeptide has been mapped to chromosome 20p13 (472) and consists of three exons: the first encodes a translocator signal, the nonapeptide hormone, the tripeptide processing signal (GKR), and the first nine residues of neurophysin; the second encodes the central part of neurophysin (residues 10-76); and the third encodes the $\mathrm{COOH}$-terminal region of neurophysin (residues 77-93/95) (Gimpl and Fahrenholtz, 2001). The vasopressin-oxytocin (VP-OT) gene locus is visualized in Figure 1. Both the OT and VP genes are highly conserved, within and between vertebrate species. Each of them have three exons, and are linked, tail-to-tail, in the genomes of all mammals. The two genes are transcribed towards each other, from opposite strands of the DNA duplex. Biosynthesis of the preprohormone starts at first in the lumen of the endoplasmic reticulum of hypothalami cells with the removal of the signal peptide (SP). The resulting prohormone protein is folded and routed to the trans-Golgi network (TGN), where it is packed specifically in the granules of the regulated secretory system. Following the signal peptide sequence, VP forms the Nterminal domain of its prohormone. This is followed by the disulphide-rich neurophysin (NP) protein, an intracellular carrier molecule. Neurophysin I (NP I) is encoded by the OT gene, and neurophysin II (NP II) by the VP gene. The VP propeptide additionally contains a C-terminal extension consisting of a 39-amino-acid glycopeptide (CPP) sequence. The VP and OT precursors are synthesized in hypothalamic cell bodies. The mature peptides are transported down axons for storage in terminals located in the neural lobe (NL) of the pituitary, from where they are released into the general blood circulation in response to physiological signals. There is a small intergenic region (the IGR) between the VP and OT genes postulated to be important for the cell-specific expression of both genes. Mapping studies indicate that the OT enhancer is more proximal to exon III of the VP gene than is the putative VP enhancer (Murphy and Wells, 2003). Studies using intact rat VP and OT constructs in transgenic mice, and rat and mouse VP genes with CAT inserts in exon II as reporters in transgenic rats and mice, respectively, have suggested the presence of cellspecific enhancer elements in the 3'-downstream (intergenic region, IGR) region of the VP gene. Evidence in favour of his view is presented from transgenic mouse studies on the expression of mouse OT- and VP-CAT gene constructs. Oxytocin and vasopressin phenotypes in the magnocellular neuronal population have traditionally been assessed by either immunocytochemical or in situ hybridization histochemical methods leading to the view that these genes are never coexpressed. More sensitive methods, however, show that most OT cells also express some VP mRNA, and most VP cells contain some OT mRNA. A third phenotype containing equivalent levels of both OT and VP mRNA can also be found under some conditions, thereby complicating the analysis of cell-specificity. A continuing problem hindering studies of the regulation of OT and VP gene expression in neurons is the lack of an appropriate cell line to examine these issues. Gainer and co-workers (2001) found that stationary slice-explant cultures allow for excellent preservation of highly differentiated magnocellular neurons in long-term culture, and that these cultures can be used for physiological and pharmacological studies and analysis of gene expression (Gainer, 1998). 
The precursor is split into the indicated fragments by enzymatic cleaves, one involving a glycyl-lysyl-arginine (GKR) sequence and leaving a carboxamide group at the $\mathrm{COOH}$-terminal end of OT.

As mentioned, OTR are abundantly expressed in the ventromedial hypothalamus (VMH) in the rat. In addition, OT functions also play an important role in the periphery as a neurohormone involved in lactation and parturition, and in the CNS, serving as a neurotransmitter involved in sexual and maternal behaviours (Telgmann et al., 2003).

\section{Receptors - gene and protein}

Genes. The identification of the complete cDNA sequence for the human OT receptor was done by Kimura et al. (1994) utilizing the expression cloning strategy. The structures of rat, pig, sheep, bovine, mouse and rhesus monkey were subsequently successfully identified.

The receptor of human oxytocin mRNA has two different sizes: $3.6 \mathrm{~kb}$ in the breast and $4.4 \mathrm{~kb}$ in the ovary, endometrium and myometrium. There is a single copy of the gene for the OT receptor in the human genome, and it is found in locus 3p25-3p26.2 (Inoue et al., 1994; Michelini et al., 1995; Simmons et al., 1995; Gimpl and Fahrenholtz, 2001). This gene is $17 \mathrm{~kb}$ long and contains 3 introns and 4 exons. Exons 1 and 2 are for the 5'-prime noncoding region, exons 3 and 4 encode the amino acids of the OT receptor. Intron 3, which is the largest at 12 $\mathrm{kb}$, separates the coding region immediately after the putative transmembrane domain 6 . Exon 4 contains the sequence encoding the seventh transmembrane domain, the $\mathrm{COOH}$ terminus, and the entire 3 '-noncoding region, including the polyadenylation signals (Gimpl and Fahrenholtz, 2001).

Normally, the G-protein-coupled receptors (GPCR) do not possess introns but, exceptionally, the gene for the OT receptor has 3 introns; the gene for human V2 receptor contains one intron at the same location after transmembrane domain 6 , similarly as the receptor-family for GnRHs. The transcription start sites lie 618 and 621 bp upstream of the initiation codon, as demonstrated by primer extension analysis. Similarly, a TATA-like motif and potential SP-1 binding site is found in the human OT receptor gene (Gimpl and Fahrenholtz, 2001). The 5'-flanking region contains in its structure: invert GATA-1 motifs, one c-Myb binding site, one AP-2 site, two AP-1 sites, and one, incomplete, ERE. Two half-palindromic 5'-GGTCA-3' motifs and one half-palindromic 5'-TGACC-3' motif of ERE have been found. Moreover, there are two nucleofactor interleukin-6 (NF IL-6) binding consensus sequences and two binding site sequences for an acute phase reactant-responsive ( Gimpl and Fahrenholz, 2001).

In the mouse OT receptor gene, the promoter region lacks an apparent TATA box but contains multiple interleukin-response elements, several halfpalindromic motifs, and a classical ERE (Kubota et al., 1996). Rat OT receptor gene expression at parturition contains three transcripts that were identified and found to differ in the length of their 3'-untranslated regions (Rozen et al., 1995). The promoter region of the rat OT receptor gene also contains multiple putative interleukin-responsive elements, NF-6, and acute-phase response elements (APRE) (Rozen et al., 1995).

Receptor protein. The OT receptor is a polypeptide 389 amino acids long with 7 transmembrane (TM) domains that belongs to the I G protein-coupled receptors (GPCR) superfamily. The active OT and VP receptor proteins are typical members of the rhodopsin-type I GPCR family (Figure 2). The seven transmembrane $\alpha$-helices are highly conserved in the prevailing receptors of the GPCR family members. Generally, conserved sequence residues in GPRCs participate in a functional mechanism activating signal transduction to the $G$ protein. In this type of receptor, the switch from the inactive to the active conformation is associated with a simultaneous change in the relative orientation of transmembrane domains 3 and 6 , after which the G protein binding sites are unmasked.

Peripheral vasopressin and oxytocin receptors have been classified on the basis of both the second messenger system coupled to the receptors and the abundant series of vasopressin and oxytocin analogues with enhanced selectivity for a certain receptor type. These classification criteria have led to the distinction of VIa vasopressin (liver, smooth muscle cells from blood vessels, and most peripheral tissues expressing vasopressin receptors), VIb vasopressin (adenohypophysis), V2 vasopressin (kidney), and oxytocin (uterus, mammary gland) receptors (Jard et al., 1988; Barberis et al., 1998).

Adenohypophysis VIb receptors also stimulate phospholipase C. Oxytocin receptors activate phospholipase $\mathrm{C}$ and induce an increase in the cytosolic $\mathrm{Ca}^{2+}$ concentration, which results in strong contractions of the uterus at term (Mirronneau, 1976; Antoni, 1986; Marc et al., 1986). Single amino acids have been found to be important for the activation of this family of receptors. In the case of the rat VIa vasopressin receptor, the functional importance of the conserved Asp97 residue in TM II has been 


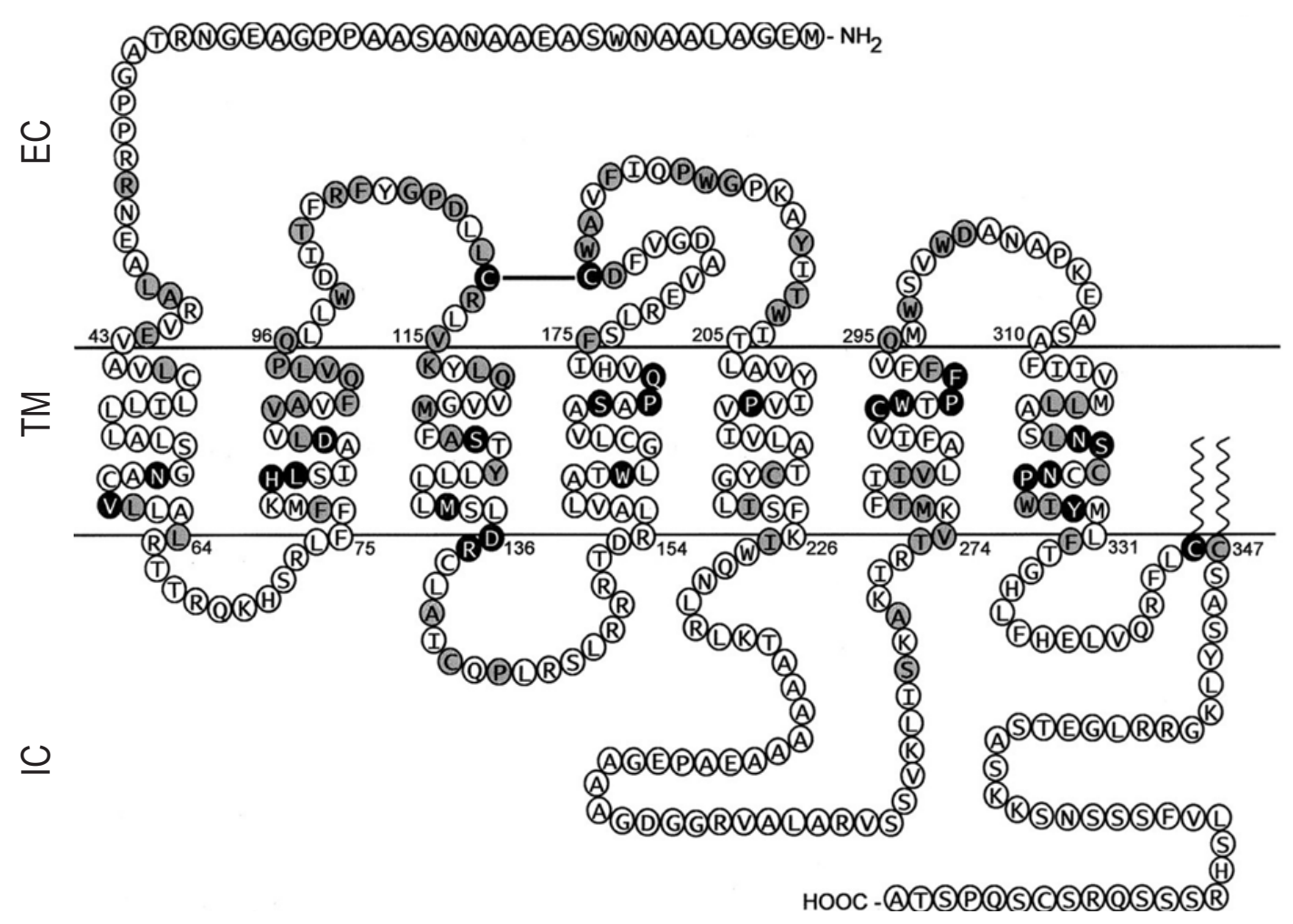

Figure 2. Structure of the human oxytocin (OT) receptor protein with amino acid residues shown in one-letter code (Gimpl and Fahrenholtz, 2001, modified). EC - extracellular domain, TM - transmembrane, IC - intracellular

confirmed later by mutational analysis; this was also found in many other GPCRs (Savarese and Fraser, 1992). In human oxytocin receptors, it was found that arginine vasopressin (AVP) may act either as a complete agonist, as demonstrated by analysis of the electrophysiological response in Xenopus oocytes (Kimura et al., 1994), or as a partial agonist, as demonstrated by measurements of the release of inositol phosphate in various cell lines. The latter property was utilized to identify amino acids that have a key role in regulating agonist-oxytocin receptor interactions. It was found that Tyr209 in the TM V and Phe284 in the TM VI of the human oxytocin receptor play such a role. Another highly conserved residue was shown to have a crucial role in the vasopressin/ oxytocin receptor activation process. The conserved Pro322 situated on TM VII in the human V2 receptor is probably necessary to allow the relative movements within the helical bundle that are required for receptor activation (Barberis et al., 1998).

Oxytocin receptors (OTR) are abundantly expressed in the ventromedial hypothalamus (VMH) in the rat brain. It is known that expression of these receptors is oestrogen-dependent, but the OTRs present in the central nucleus of amygdala do not appear to be so. The gene was isolated from a rat genomic library and its protomer region analysed for response elements. Several regulatory elements of interest were identified, including cyclic adenosine monophosphate (cAMP) response element (CRE), a serum response element (SRE), several activator protein-1 elements (AR-1) in addition to a palindromic oestrogen response element (ERE). In transfection assays, protein kinase $\mathrm{C}$ (PKC) and protein kinase dependent on cAMP (PKA) activation by phorbol ester and forskolin treatment optimally enhanced the transcription of the OTR (Fanelli et al., 1999; Telgmann et al., 2003).

VP and OT strongly modulate autonomic fear responses, although the mechanisms of that are not quite clear. Certainly, their action is through the network of their receptors abundantly present in the central and autonomic nervous systems. These neuropeptides excite distinct neuronal populations in the central amygdala, which provides the major output of the amygdaloid complex to the autonomic nervous system (Huber et al., 2005). These authors identified two neuronal populations as part of an inhibitory network through which VP and OT modulate the integration of excitatory information from the basolateral amygdala and cerebral cortex, in opposite manners. Through this network, the expression and endogenous activation of VP and OT receptors may regulate the autonomic expression of fear (Huber et al., 2005).

The possibility of research, in the near future, with high-resolution structures of vasopressin and 
oxytocin receptors will greatly facilitate establishing the precise three-dimensional models of these receptors and subsequently, obtaining new knowledge on the receptor domains responsible for agonist or antagonist binding and for $\mathrm{G}$ protein activation. This understanding of the kernel of receptor function, at a molecular level, will then be a useful tool in the development of new molecules with high selectivity for the different subtypes of receptors, and thus in the development of new molecules of potential therapeutic interest (Barberis et al., 1998).

\section{Evolution}

Delineation of genomes is the key to following the evolution of neuropeptides and their receptors. Current methods of molecular biology enable finding true orthologues (species homologue) and paralogues (gene duplicates), which is extremely important in successful comparative research on neuropeptides such as oxytocin and vasopressin. Orthologues may be identified by comparing the location (synteny) between species. The importance of this is great because they have relatively short chains and possess several invariant positions. In this work, confusion has arisen due to the old custom of giving names to peptides from the first species in which the sequence was discovered and determined; a good example of this is the chicken GnRH (GnRH II), or giving the names that point out amino acid differences, like Lys-vasopressin.

In recent studies, the sequenced genomes have made it possible to precisely indicate the orthologue and paralogue by location of the genes relative to neighbouring genes on the chromosomes (Larhammar et al., 2009). The obtained genome databases are able to provide a complete list of the individual family members in particular species. A number of gene families in vertebrates have expanded in the two basal tetraploidizations (2R) and teleost fish third tetraploidization (3R), after which some vertebrate lineages lost some of the duplicates. The exact time points for the two tetraploidizations, relative to the divergence of the cyclostome lineages comprised by hagfishes and lampreys, will become more evident after obtaining more extensive sequence data from species representing these two lineages (Larhammar et al., 2009). The current results and evidence show that one tetraploidization took place before the cyclostome-gnathostome divergence and one tetraploidization happened after this in the gnathosome ancestor (Escriva et al., 2002; Stadler et al., 2004). These tetraploidizations do not fully explain the gene duplications in all vertebrates. Many duplications of vertebrate genes occurred by other mechanisms, often by local duplications serving to maintain the orientation of the gene, as in tandem duplications. Sometimes one duplicate is inverted relative to the other, either in a head-to-head or tailto-tail configuration. These mechanisms work very usefully also within the other gene families, such as peptide receptors. It is relatively well established that all euteleosts share a common ancestor that underwent a third tetraploidization (3R). Sturgeons branched off before the teleost tetraploidization but seem to have undergone an independent third tetraploidization, followed by diploidization (Fontana et al., 2008; Larhammar et al., 2009).

\section{Evolution of oxytocin and vasopressin structures}

As already mentioned, oxytocin (OT) and vasopressin (VP), and all of the hormones related to them, consist of nine-amino acid long chains with the cysteine residues in positions 1 and 6 forming a cyclic six-amino acid structure, and with the $\mathrm{C}$ terminal glycine in $\alpha$-amidated form. These neuropeptides are classified into oxytocin and vasopressin families based on the presence of a particular amino acid residue in position 8 . The oxytocin family contains a neutral amino acid in this position, the vasopressin family contains a basic amino acid, lysine or arginine. The isoleucine residue in position 3 is important in the stimulation of OT receptors, while the Arg or Lys residue in position 8 is important in vasopressin receptor stimulation (Acher et al., 1995; Gimpl and Fahreholtz, 2001). The differences in the polarity of the residues in the chain are considered to be what allows the vasopressin and oxytocin peptides to interact with the particular receptors (Barberis et al., 1998).

OT-like and VP-like peptides are present in every vertebrate species. Bony fishes (Osteichthyes), ancestors of the land vertebrates, have isotocin and vasotocin. Current knowledge indicates that there are two evolutionary structural lineages of neuropeptides: the isotocin-mesotocin-OT line, associated with the functions in reproductive actions, and the vasotocin-VP line participating in water homeostasis. Vasotocin was detected in the most primitive cyclostomes, the OT and VP genes may have arisen by duplication of a common ancestral gene after the irradiation of cyclostomes (Gimpl and Fahreholtz, 2001).

The ancestral gene, encoding the precursor preprohormone, has been present in the animal genome for more than 600 million years, during which the evolution of these neurohormones occurred. Evidence for its presence for such a long period was 
deduced on the basis of special calculations on the nucleotide level. The surprising exceptionally high stability of the structure of these nine-amino acid chains during the whole long process of evolution, points to the existence of very powerful selective pressure, possibly the functionally parallel evolution of the respective, cognate receptors and specific, necessary processing enzymes, both precursor structures and processing enzymatic machinery to build the specific conformations. Substitutions, which may be neutral or selective, occurred in precise positions (Acher et al., 1995; Gimpl and Fahreholtz, 2001).

An extraordinary and surprising diversity of OT-like peptides has been detected in cartilaginous fishes (Chondrichthyes). These marine fishes utilize urea rather than salts for osmoregulation. The OTlike hormones achieved a high diversity in Chondrichthyes as they were relieved from the control of ionic homeostasis (Acher et al., 1995). Oxytocin, the typical neurohormone of placental mammals, was found in the Pacific ratfish (a Chondrichthyes species) (Gimpl and Fahrenholtz, 2001).

Mesotocin is the OT-like neurohormone prevalent in terrestrial vertebrate species from lungfishes to marsupials, including all nonmammalian tetrapods (amphibians, reptiles, and birds). Only two South American marsupials synthesize OT exclusively, whereas all other marsupials possess mesotocin. In the Northern brown bandicoot (Isoodon macrourus) (Rouille et al., 1988) and the North American opossum (Dilelphis virginiana) (Chauvet et al., 1985), OT is present together with mesotocin. According to all results, mesotocin has the largest distribution in vertebrates after vasotocin, identified in all nonmammalian vertebrates, and isotocin, found in bony fishes. It is not known whether the marsupial species that possess both OT and mesotocin, have two separate receptors for them. The earthworm, Eisenia foetida, is the most primitive species in which annetocin, an OT-related peptide, has been found and identified. Injection of annetocin into the earthworm or leech induces egg-laying behaviour (Oumi et al., 1996; Gimpl and Fahrenholtz, 2001).

Neurohypophysial peptides are a very ancient family of hormones with representatives found in diverse species of invertebrates and vertebrates. Invertebrates contain either a vasopressin-family peptide or an oxytocin-family peptide (Table 1) but very seldom have both peptides.

Although some invertebrates like octopus have two peptides, cephalotoxin and octopressin, both are oxytocin-like peptides (Reich, 1992; TakuwaKuroda et al., 2003). In contrast to invertebrates, all jawed vertebrates have at least one member each from the vasopressin- and oxytocin-families. In jawless vertebrates, only a vasotocin gene has been cloned so far. In the study of Gwee et al. (2009), the authors sequenced the neurohypophysial gene loci in a cartilaginous fish, the elephant shark, and a jawless vertebrate, the Japanese lamprey. They also characterized this locus in the genome of amphioxus, a cephalochordate. The results showed that both amphioxus and lamprey contain a single neurophypophysial hormone gene that encodes a basic vasopressin-family peptide; elephant shark contains both a vasopressin-family gene and an oxytocin-family gene that are closely linked tail-to-head.

The living chordates are classified into three major lineages, the cephalochordates (e.g., amphioxus), urochordates (tunicates), and vertebrates. The cephalochordates are the most basal group of chordates and the urochordates are the 'sisters' of vertebrates (Putnam et al., 2008). Recently, a whole-genome sequence of a cephalochordate, the amphioxus, has been completed (Putnam et al., 2008; Gwee et al., 2009).

A study on the expression pattern of the vasotocin gene in lamprey has shed light on the ancestral expression pattern, and how it has diverged in the daughter genes. This study was successfully done by the group of Gwee et al. (2009). The tail-tohead orientation of the elephant shark vasotocin and oxytocin genes indicates that this was the ancestral state of the two genes soon after the duplication of the vasotocin gene. The close linkage and organization of these genes have been conserved in a coelacanth, Xenopus, and in chicken and opossum genomes, while the oxytocin gene has undergone a local inversion in human and rodent genomes. In contrast to these vertebrates, the neurohypophysial hormone gene locus in pufferfishes has undergone extensive rearrangements (Gwee et al., 2009). The isotocin gene in fugu has been translocated to a position upstream of the vasotocin gene and the two genes are separated by five unrelated genes. The two genes located downstream of the vasotocin gene in fugu (CLI and UGNT) are unrelated to the genes present at a similar position (Gnrh2 and Ptpra) in other vertebrates. A search for the neurohypophysial hormone genes in the genome assemblies of other teleost fishes such as the stickleback, medaka and zebrafish on the UCSC Genome Browser (Cruz et al., 1987; Gwee et al., 2009) revealed that while the arrangements of isotocin and vasotocin genes in stickleback (ChrXIII) and medaka (Chr9) are similar to that in fugu, the two genes are located on separate chromosomes ( $\mathrm{Chr} 5$ and Chr8, respectively) in zebrafish. That means that the hormone gene locus has undergone extensive 
Table 1. Oxytocin, vasopressin and related natural peptides. Cysteine (Cys) in position 1 forms disulphide bridge with cysteine (Cys) position 6 (Acher et al.,1995; Gimpl and Fahrenholtz, 2001; Gwee et al., 2009, modified)

\begin{tabular}{|c|c|c|c|c|c|c|c|c|c|c|}
\hline & 1 & 2 & 3 & 4 & 5 & 6 & 7 & 8 & 9 & \\
\hline Oxytocin & Cys & Tyr & Ile & Gln & Asn & Cys & Pro & Leu & Gly $\left(\mathrm{NH}_{2}\right)$ & $\begin{array}{l}\text { Placentals, some marsupials, } \\
\text { ratfish (Hydrolagus colliei) }\end{array}$ \\
\hline Mesotocin & Cys & Tyr & lle & Gln & Asn & Cys & Pro & lle & Gly $\left(\mathrm{NH}_{2}\right)$ & $\begin{array}{l}\text { Marsupials, nonmammalian } \\
\text { tetrapods, lungfishes }\end{array}$ \\
\hline Isotocin & Cys & Tyr & lle & Ser & Asn & Cys & Pro & Ile & Gly $\left(\mathrm{NH}_{2}\right)$ & Osteichthyes \\
\hline Glumitocin & Cys & Tyr & lle & Ser & Asn & Cys & Pro & Gln & Gly $\left(\mathrm{NH}_{2}\right)$ & Skates (Chondrichthyes) \\
\hline Valitocin & Cys & Tyr & lle & Gln & Asn & Cys & Pro & Val & Gly $\left(\mathrm{NH}_{2}\right)$ & Sharks (Chondrichthyes) \\
\hline Aspargtocin & Cys & Tyr & lle & Asn & Asn & Cys & Pro & Leu & Gly $\left(\mathrm{NH}_{2}\right)$ & Sharks (Chondrichthyes) \\
\hline Asvatocin & Cys & Tyr & lle & Asn & Asn & Cys & Pro & Val & Gly $\left(\mathrm{NH}_{2}\right)$ & Sharks (Chondrichthyes) \\
\hline$\left[\mathrm{Phe}^{2}\right]$ mesotocin & Cys & Phe & lle & Gln & Asn & Cys & Pro & Ile & Gly $\left(\mathrm{NH}_{2}\right)$ & Australian lungfish \\
\hline Phasitocin & Cys & Tyr & Phe & Asn & Asn & Cys & Pro & Ile & Gly $\left(\mathrm{NH}_{2}\right)$ & Sharks (T. scyllium) \\
\hline Phasvatocin & Cys & Phe & Phe & Asn & Asn & Cys & Pro & Val & Gly $\left(\mathrm{NH}_{2}\right)$ & Sharks (Chondrichthyes) \\
\hline Cephalotocin & Cys & Tyr & Phe & $\operatorname{Arg}$ & Asn & Cys & Pro & Ile & Gly $\left(\mathrm{NH}_{2}\right)$ & Octopus vulgaris (cephalopod) \\
\hline Annetocin & Cys & Tyr & Val & Arg & Asn & Cys & Pro & Thr & Gly $\left(\mathrm{NH}_{2}\right)$ & Eisenia foetida (Annelids) \\
\hline Vasotocin & Cys & Tyr & lle & GIn & Asn & Cys & Pro & $\operatorname{Arg}$ & Gly $\left(\mathrm{NH}_{2}{ }^{2}\right)$ & $\begin{array}{l}\text { Nonmammalian vertebrates, } \\
\text { cyclostomes }\end{array}$ \\
\hline Vasopressin & Cys & Phe & Phe & Gln & Asn & Cys & Pro & Arg & Gly $\left(\mathrm{NH}_{2}\right.$ & Mammals \\
\hline Lys ${ }^{8}$-pressin & Cys & Phe & Phe & Gln & Asn & Cys & Pro & Lys & Gly $\left(\mathrm{NH}_{2}^{2}\right)$ & Pig, some marsupials \\
\hline Phenypressin & Cys & Phe & lle & Gln & Asn & Cys & Pro & Arg & Gly $\left(\mathrm{NH}_{2}\right)$ & Macropodids (Marsupials) \\
\hline Locupressin & Cys & Leu & lle & Thr & Asn & Cys & Pro & Arg & Gly $\left(\mathrm{NH}_{2}\right)$ & Locusta migratoria (Insects) \\
\hline $\operatorname{Arg}^{8}$-conopressin & Cys & Ile & lle & $\operatorname{Arg}$ & Asn & Cys & Pro & Arg & Gly $\left(\mathrm{NH}_{2}\right)$ & Conus geographicus (Molluscs) \\
\hline Lys $^{8}$-conopressin & Cys & Phe & Phe & $\operatorname{Arg}$ & Asn & Cys & Pro & Lys & Gly $\left(\mathrm{NH}_{2}\right)$ & Lymnaea stagnalis (Molluscs) \\
\hline
\end{tabular}

rearrangements in teleost fishes, in contrast to its well conserved synteny in other vertebrates, including the jawless lamprey. These results are in accordance with previous observations that teleost fish genomes have experienced a higher rate of chromosomal rearrangements compared with other vertebrates (Ravi and Venkatesh, 2008; Gwee et al., 2009).

The rearrangements in teleost fishes might be related to the 'fish-specific' whole-genome duplication that occurred in the teleost ancestor (Christoffels et al., 2004; Jaillon et al., 2004; Gwee et al., 2009). The duplicated gene loci generated by this whole-genome duplication might have facilitated rearrangements between paralogous chromosomal segments through homologous recombination (Gwee et al., 2009).

In its laborious and intensive work, the eminent research group led by Gwee et al. (2009) tried to build a phylogenetic tree of invertebrate and vertebrate neurohypophysial hormone genes and obtained as a result an anomalous gene tree in which elephant shark, coelacanth and mammals clustered the vasopressin- and oxytocin-family genes in fugu, with each other, suggesting that the two genes originated independently in each lineage. Because this is highly unlikely, it should be suggested that this result was probably an artefact in the data analysis. Therefore, further investigations are necessary for the proper clarification of these results and finally to make the necessary corrections in these estimations.

This advanced group of researchers (Gwee et al., 2009) did, however, do a large amount of work in the area of evolution of neuropeptide structure and in the relationships between their genes during the process of evolution. They characterized the neurohypophysial hormone locus in elephant shark (a cartilaginous fish), Japanese lamprey (a jawless vertebrate), and amphioxus (a cephalochodate). They also showed that amphioxus and lamprey each contain a single gene belonging to the vasopressin family, while elephant shark contains a vasopressin-family and an oxytocin-family gene that are closely linked in a tail-to-head orientation. These results indicate that vasopressin- and oxytocin-family peptides evolved in a common ancestor of jawed vertebrates through tandem duplication of the ancestral vasotocin gene. The vasotocin and oxytocin genes in elephant shark exhibit distinct expression patterns.

The achievements of this research group in the further clarification of neurohormone evolution should be specially and gratefully acknowledged. These authors precisely indicated that this is a classic example for the origin of a novel gene with a distinct function and expression pattern througtion) and order of genes in the neurohypophysial hormone 
duplication of an ancestral gene. The synteny (location) and order of genes in the neurohypophysial hormone gene locus are conserved in lampreys, elephant sharks, coelacanths and tetrapods, but disrupted in teleost fishes, presumably due to the rearrangements facilitated by a whole-genome duplication event in the teleost fish ancestor (Gwee et al., 2008, 2009).

\section{General and final considerations on evolution}

Modern molecular biology, utilizing very powerful analytical methods, is ready to direct the research from the study of whole animal organisms to the level of gene systems. The availability of this approach released a veritable avalanche of research and information that culminated in its apogee, the delineation of the sequence of the entire human genome, one of the greatest prides and triumphs of our scientific civilization (Murphy and Wells, 2003). The new challenge, which appeared for neuroendocrinologists, is to utilize sequence data in systems studies that will increase our understanding of the kernel of molecular and cellular mechanisms regulating homeostasis and evolution.

It should be stressed that the mammalian neurohormones, OT and VP, have been known for a relatively long time and their homologous peptides have been identified in species representing all gnathosome classes. These peptides in different species, which have different amino acid residues in one or more positions of the chain sequence in mammals, have received different names. Vasotocin is present in all nonmammalian gnathosomes and differs by one residue different from the sequence of mammalian vasopressin. Mesotocin and isotocin have one or two different amino acid residues different from oxytocin, respectively. New sequence data and sequences of the prepropeptides, make it possible to classify vasotocin as orthologous to vasopressin, while isotocin and vasotocin, as orthologous to oxytocin (Larhammar et al., 2009).

Many unknown sequences and evolutionary pathways have been resolved by the very important research results of the comparative study of the genes in the coelacanth Latimeria manadoensis and several tetrapods and teleost fishes by the outstanding research team of Vankatesh (Gwee et al., 2008, 2009; Larhammar et al., 2009).

The authors demonstrated without any doubt that vasopressin and vasotocin are orthologous in two major vertebrate clades comprised by rayfinned and lobe-finned fishes. The comparative study was also able to explain the third peptide found in marsupials. The opossum (Monodelphis domestica) chromosome possesses a duplicated vasopressin- oxytocin (mesotocin) gene pair whereupon the vasopressin duplicate has undergone one amino acid residue change in which $\mathrm{Arg}^{8}$ was replaced by lysine, hence the name $\mathrm{Lys}^{8-}$ vasopressin for the vasopressin (VP) variant (Larhammar et al., 2009).

The delineation of other neuropeptide sequences and structures and the structure of their genes will enable increasingly better understanding of evolutionary events and mechanisms, but also establishing more rational terminology of many neuropeptide and receptor families (Larhammar et al., 2009).

\section{References}

Acher R., 1996. Molecular evolution of fish neurohypophysial hormones: neural and selective evolutionary mechanisms. Gen. Comp. Endocrinol. 102, 157-172

Acher R., Chauvet J., Chauvet M.T., 1995. Man and the chimaera. Selective versus neutral oxyticin evolution. Adv. Exp. Med. Biol. 395, 615-627

Antoni F.A., 1986. Oxytocin receptors in rat adenohypophysis: evidence from redioligand binding studies. Endocrninology 119, 2393-2395

Arima H., Kondo K., Kakiya S., Nagasaki H., Yokoi H., Yambe Y., Murase T., Iwasaki Y., Oiso Y., 1990. Rapid and sensitive vasopressin heteronuclear RNA responses to changes in plasma osmolality. J. Neuroendocrinol. 11, 337-341

Barberis C., Mounillac B., Durroux T., 1998. Structural bases of vasopressin/oxytocin receptor function. J. Endocrinol. 156, 223-229

Bargman W., 1966. Neurosecretion. Int. Rev. Cytol. 19, 183-201

Boersma C.J., Sonnemans M.A., Van Leeuwen F.W., 1993. Immunoelectron microscopic demonstration of oxytocin and vasopressin in pituicytes and in nerve terminals forming synaptoid contacts with pituicytes in the rat neural lobe. Brain Res. 611, $117-129$

Bourque C.W., Oliet S.H., Richard D., 1994. Osmoreceptors, osmoreception, and osmoregulation. Front Neuroendocrinol. 15, 231-274

Brownstein M., Russel J., Gainer H., 1980. Synthesis, transport and release of posterior pituitary hormones. Science 207, 373-378

Burbach J.P.H., de Hoop M.J., Schmale H., Richter D., de Kloet E.R., Ten Haaf J.A., de Wied D., 1984. Differential responses to osmotic stress of vasopressin-neurophysin mRNA in hypothalamic nuclei. Neuroendocrinology 39, 582-584

Burkhardt T., Schwabe S., Morgenthaler N.G., Natalucci G., Zimmermann R., Wellmann S., 2012. Copeptin: a marker for stress reaction in fetuses with intrauterine restriction. Amer. J. Obstet. Ginecol. 207, 497, e1-5

Carter D.A., Murphy D., 1991. Nuclear mechanisms mediate rhythmic changes in vasopressin mRNA expression in the rat suprachiasmatic nucleus. Mol. Brain Res. 12, 315-321

Chaturvedi C.M., Zheng Z., Shimada K., Cornett L.E., Koike T.I., 1996. Changes in poly $(A)$ tail length of arginine vasotocin messenger ribonucleic acid in the hypothalamus of water-deprived chickens. Gen. Comp. Endocrinol. 103, 316-322

Chauvet J., Hurpet D., Colne T., Michel G., Chauvet M.T., Acher R., 1985. Neurohypophysial hormones as evolutionary tracers: identification of oxytocin, lysine vasopressin, and argininr vasopressin in two South American opossums (Didelphis marsupialis and Philander opossum). Gen. Comp. Endocrinol. 57, 320-328

Christoffels A., Koh E.G., Chia J.M., Brenner S., Aparicio S., Venkatesh B., 2004. Fugu genome analysis provides evidence for a whole-genome duplication early during the evolution of rayfinned fishes. Mol. Biol. Evol. 21, 1146-1151 
Cruz L.J., de Santos V., Zafaraila G.C., Ramilo C.A., Zeikus R., Gray W.R., Olivera B.M., 1987. Invertebrate vasopressin/ oxytocin homologs. Characterization of peptides from Conus geographus and Conus straitus venoms. J. Biol. Chem. 262, 15821-15824

Davies J., Waller S., Zeng Q., Wells S., Murphy D., 2003. Further delineation of the sequence required for the expression and physiological regulation of the vasopressin gene in transgenic rat hypothalamic magnocellular neurones. J. Neuroendocrinol. 15, 42-50

de Bree F.M., Knight D., Murphy D., 2000. Sorting of the vasopressin prohormone into the regulated secretory pathway. FEBS Lett. $475,175-180$

Escriva H., Manzon L., Youson J., Laudet V., 2002. Analysis of lamprey and hagfish genes reveals a complex history og gene duplications during early vertebrate evolution. Mol. Biol. Evol. 19, 1440-11450

Fanelli F., Barbier P., Zanchetta D., De Bendetti P.G., Chini B., 1999. Activation mechanism of human oxytocin receptor : a combined study of experimental and computer-stimulated mutagenesis. Mol. Pharmacol. 56, 214-225

Fontana F., Congiu L., Mudrak V.A., Quattro J.M., Smith T.I., Ware K., Doroshov S.I., 2008. Evidence of hexaploid karyotype in shortnose sturgeon. Genome 51, 113-119

Gainer H., 1998. Cell-specific gene expression in oxytocin and vasopressin magnocellular neurons. Adv. Exp. Med. Biol. 449, 15-27

Gainer H., Fields R.L., House S.B., 2001. Vasopressin gene expression. Experimental models and strategies. Exp. Neurol. 171, 190-199

Gainer H., Wray S., 1994. Cellular and molecular biology of oxytocin and vasopressin. In: E. Knobil, J.D. Neil (Editors). Physiology of Reproduction, pp. 1099-1129

Gillies G.E., Linton E.A., Lowry P.J., 1982. Corticotropin releasing activity of the new $C R F$ is potentiated several times by vasopressin. Nature 299, 355-357

Gimpl G., Fahreholtz F., 2001. The oxytocin receptor system; structure function, and regulation. Physiol. Rev. 81, 629-683

Glasgow E., Kusano K., Chin H., Mezey E., Young W.S. III, Gainer H., 1999. Single cell reverse transcription-polymerase chain reaction analysis of rat supraoptic magnocellular neurons: neuropeptide phenotypes and high voltage-gated calcium channel subtypes. Endocrinology 140, 5391-5401

Gwee P.C., Amemiya C.T., Brenner S., Venkatesh B., 2008. Sequence and organization of coelacanth neurohypophysial hormone genes: evolutionary history of the vertebrate neurohypophysial hormone gene locus. BMC Evol. Biol. 8, 93; online at: http://www. biomedcentral.com/1471-2148/8/93

Gwee P.-C., Tray B.-H., Brenner S., Venkatesh B., 2009. Characterization of the neurohypophysial hormone gene loci in elephant shark and the Japanese lamprey: origin of vertebrate neurohypophysial hormone genes. BMC Evol. Biol. 9, 47; online at: http://www.biomedcentral. com/1471-2148/9/47

Herman J.P., Schafer M.K.-H., Watson S.J., Scherman T.G., 1991. In situ hybridisation analysis of arginine vasopressin gene transcription using intron specific probes. Mol. Endocrinol. 5 , 1447-1456

Hoyle C.H., 1999. Neuropeptide families and their receptors: evolutionary perspectives. Brain Res. 848, 1-25

Huang W., Lee S.L., Amason S.S., Sjoquist M.,1996. Dehydration natriuresis in male rats is mediated by oxytocin. Amer. $\mathrm{J}$. Physiol. 270, R427-R433

Huber D., Veinante P., Stoop R., 2005. Vasopressin and oxytocin excite distinct neuronal populations in the central amygdala. Science 308, 245-248
Inoue T., Kimura T., Azuma C., Inazawa J., Takemura M., Kikuchi T., Kubota Y., Ogita K., Saji F., 1994. Structural organization of the human oxytocin receptor gene. J. Biol. Chem. 269, 32451-32456

Ivell R., Walther N., Wehrenberg U., McArdle C., Ungefroren H., 1993. The regulation of neurohypophysial peptide gene expression in gonadal tissues. Regul. Peptides 45, 263-267

Jaillon O., Aury J.M., Brunet F., Petit J.L., Strange-Thomann N., Mauceli E., Bouneau L., Fisher C., Ozouf-Costaz C., Bernot A., et al., 2004. Genome duplication in the teleost fish Tetraodon nigriviridis reveals the early vertebrate proto-karyotype. Nature 431, 946-957

Jard S., Elands J., Schmidt A., Barberis C., 1988. Vasopressin and oxytocin receptors: an overview. In: H. Imura, K. Shizume (Editors). Progress in Endocrinology. Amsterdam, Elsevier, pp. $1183-1188$

Kimura T., Makino Y., Saji F. et al., 1994. Molecular characterization of a cloned human oxytocin receptor. Eur. J. Endocrinol. 131, 385-390

Kubota Y., Kimura T., Hashimoto K., Tokugawa Y., Nobunaga K., Azuma C., Saji F., Murata Y., 1996. Structure and expression of the mouse oxytocin receptor gene. Mol. Cell Endocrinol. $124,25-32$

Larhammar D., Sundstrom G., Dreborg S., Daza D.O., Larsson T.A., 2009. Major genomic events and their consequences for vertebrate evolution and endocrinology. Trends Comp. Endocrinol. Neurobiol. 1163, 201-208

Levy A., Lightman S.L., Carter D.A., Murphy D., 1990. The origin and regulation of posterior pituitary vasopressin ribonucleic acid in osmotically stimulated rats. J. Neuroendocrinol. 3, 329-334

Ma X.M., Levy A., Lightman S.L., 1997. Emergence of an isolated arginine vasopressin (AVP) response to stress after repeated restraint: a study of both AVP and corticotropin-releasing hormone messenger ribonucleic acid (RNA) and heteronuclear RNA. Endocrinology 138, 4351-4357

Marc S., Leiber D., Harbon S., 1986. Carbachol and oxytocin stimulate the generation of inositol phosphates in guinea pig myometrium. FEBS Lett. 201, 9-10

Maciejewski-Lenoir D., Jirikowski G.F., Sanna P.P., Bloom F.E., 1993. Reduction of exogenous vasopressin RNA poly(A) tail length increases its effectiveness in transiently correcting diabetes insipidus in the Brattleboro rat. Proc. Nat. Acad. Sci. USA 90, 1435-1439

Małyszko J., Koc-Żórawska, Koźmiński P., Małyszko J.S., Żórawski M., Myśliwiec M., 2010. Copeptin in haemodialysed patients (in Polish). Nefrol. Dial. Pol. 14, 182-184

Michelini S., Urbanek M., Dean M., Goldman D., 1995. Polymorphism and genetic mapping of the human oxytocin receptor gene on chromosome 3. Amer. J. Med. Genet. 60, 183-187

Mirronneau J., 1976. Effects of oxytocin on ionic currents underlaying rhytm activity and and contraction in uterine smooth muscle. Pflüger's Arch. 363, 113-116

Mohr E., Fehr S., Richter D., 1991. Axonal transport of neuropeptide encoding mRNAs within the hypothalamo-hypophyseal tract of rats. EMBO J. 10, 2419-2424

Moore R.Y., 1983. Organization and function of a central nervous system circadian oscillator: a suprachiasmatic hypothalamic nucleus. Fed. Proc. 42, 2783-2789

Murphy D., Ang H.L., Zeng Q., Ho M.Y., Funkhouser J., Carter D., 1992. Neuropeptide gene expression in transgenic animals. Prog. Brain Res. 92, 77-96

Murphy D., Carter D.A., 1990. Vasopressin gene expression in the rodent hypothalamus: transcriptional and pos-transcriptional responses to physiological stimulation. Mol. Endocrinol. 4, 1051-1059 
Murphy D., Funkhouser J., Ang H.-L., Foo Ch., Carter D., 1993. Extrahypothalamic expression of the vasopressin and oxytocin genes. Ann. NY Acad. Sci. 689, 91-106

Murphy D., Levy A., Lightman S., Carter D., 1989. Vasopressin RNA in the neural lobe of the pituitary: dramatic accumulation in response to salt loading. Proc. Nat. Acad. Sci. USA 86, 9002-9005

Murphy D., Wells S., 2003. In vivo gene transfer studies on the regulation and function of the vasopressin and oxytocin genes. J. Neuroendocrinol. 15, 109-125

Oumi T., Ukena K., Matsushima O., Ikeda T., Fujita T., Minakata H., Nomoto K., 1996. Annetocin, an annelid oxytocin-related peptide, induces egg-laying behavior in the earthworm, Eisenia foetida. J. Exp. Zool. 276, 151-156

Pu L.P., Van Leeuwen F.W., Fracer H.L.T., Sonnemans M.A., Loh Y., 1995. Localization of vasopressin mRNA and immunoreactivity in pituicytes of pituitary stalk-transected rats after osmotic stimulation. Proc. Nat. Acad. Sci. USA 92,10653-10657

Putnam N.H., Butts T., Ferrier D.E., Furlong R.F., Hellsten U., KawashimaT., Robinson-Rechavi M., Shoguchi E., Terry A., Yu J.K., 2008. The amphioxus genome and the evolution of the chordate karyotype. Nature 453, 1064-1071

Ratty A.K., Jeong S.-W., Nagle J.W., Chin H., Gainer H., Murphy D., Venkatesh B., 1996. A systemic survey of the intergenic region between the murine oxytocin- and vasopressin encoding genes. Gene 174, 71-78

Ravi V., Venkatesh B., 2008. Rapidly evolving fish genomes and teleost diversity. Curr. Opin. Genet. Develop. 18, 544-550

Reich G., 1992. A new peptide of the oxytocin/vasopressin family isolated from nerves of the cephalopod Octopus vulgaris. Neurosci. Lett. 134,191-194

Reeves W.B., Andreoli T.E., 1992. The posterior pituitary and water metabolism. In: I.D. Wilson, D.W. Foster (Editors). Williams Textbook of Endocrinology. Philadelphia, WB Saunders, pp. $311-256$

Rouille Y., Chauvet M.T., Chauvet J., Acher R., 1988. Dual duplication of neurohypophysial hormones in an Australian marsupial: mesotocin, oxytocin, lysine vasopressin and arginine vasopressin in a single gland of northern bandicoot (Isoodon macrourous). Biochem. Biophys. Res. Commun. 154, 346-350

Rozen F., Russo C., Banville D., Zingg H.H., 1995. Structure, characterization, and expression of the rat oxytocin receptor gene. Proc. Nat. Acad. Sci. USA 92, 200-204

Russell J.A., Leng G., 1998. Sex, parturition and motherhood without oxytocin. J. Endocrinol. 57, 343-359

Savarese T., Fraser C., 1992. In vitro mutagenesis and the search for structure-function relationships among $\mathrm{G}$ protein-coupled receptors. Biochem. J. 283, 1-19
Schmitz E., Mohr E., Ricgter D., 1991. Rat vasopressin and oxytocin genes are linked by long interspersed repeated DNA element (LINE), sequence and transcriptional analysis of LINE. DNA Cell Biol. 10, 81-91

Simmons Jr. Ch., Clancy T.E., Quan R., Knoll J.H., 1995. The oxytocin receptor gene (OXTR) localizes to human chromosome 3p25 by fluorescence in situ hybridization and PCR analysis of somatic cell hybrids. Genomics 26, 623-625

Stadler P.F., Fried C., Prohaska S.J., Bailey W.J., Misof B.Y., Ruddle F.H., Wagner G.P., 2004. Evidence for independent Hox gene duplications in the hagfish lineage; a PCR-based gene inventory of Eptatretus stoutii. Mol. Phylogenet. Evol. 32, 686-694

Takuwa-Kuroda K., Iwakoshi-Ukena E., Kanda A., Minakata H., 2003. Octopus, which owns the most advanced brain in invertebrates, has two members of vasopressin/oxytocin superfamily as in vertebrates. Regul. Peptides 115, 139-149

Telgmann R., Bathgate R.A., Jaeger S., Tillmann G., Ivell R., 2003. Transcriptional regulation of the bovine oxytocin receptor gene. Biol. Reprod. 68, 1015-1026

Trembleau A., Morales M., Bloom F.E., 1994. Aggregation of vasopressin $\mathrm{mRNA}$ in a subset of axonal swellings of the median eminence and posterior pituitary: light and electron microscopic evidence. J. Neurosci. 14, 39-53

Trembleau A., Morales M., Bloom F.E., 1996. Differential compartmentalization of vasopressin messenger RNA and neuropeptide within the rat hypothalamo-neurohypophysial axonal tracts: light and electron microscopic evidence. Neuroscience $70,113-125$

Vandesande F., Dierickx K., De Mey J., 1977. The origin of the vasopressinergic and oxytocinergic fibers of the external region of the median eminence of the rat hypophysis. Cell Tissue Res. 180, 443-452

Van Tol H.H., Bolwerk E.L., Liu B., Burbach J.P., 1988. Oxytocin and vasopressin gene expression in the hypothalamo- neurohypophyseal system of the rat during the estrus cycle, pregnancy, and lactation. Endocrinology 122, 985-951

Verbalis J.G., Magnione M.P., Stricker E.M., 1991. Oxytocin produces natriuresis in male rats at physiological plasma concentrations. Endocrinology 128, 1317-1322

Xi D., Kusano K., Gainer H., 1999. Quantitative analysis of oxytocin and vasopressin messenger ribonucleic acids in single magnocellular neurons isolated from supraoptic nucleus of rat hypothalamus. Endocrinology 140, 4677-4682

Zingg H.H., Lefebvre D., Almazan G., 1986. Regulation of vasopressin gene expression in hypothalamic neurons. J. Biol. Chem. 261, 12956-12959 